\title{
GASTRO-FLOATING TABLETS OF REPAGLINIDE: PREPARATION AND IN VIVO EVALUATION
}

\author{
POORNIMA P ${ }^{1 *}$, ABBULU K², MUKKANTI K ${ }^{1}$
}

${ }^{1}$ Jawaharlal Nehru Technological University Hyderabad, Kukatpally, Hyderabad - 500 072, Telangana, India. ${ }^{2} \mathrm{CMR}$ College of Pharmacy, Kandlakoya (V), Hyderabad - 501 401, Telangana, India. Email: pamupoornima@gmail.com

Received: 09 March 2018, Revised and Accepted: 12 April 2018

ABSTRACT

Objective: Current research concerns the expansion of repaglinide matrix floating tablets, which are designed to prolong the gastric residence time, increase the drug bioavailability, and diminish the side effects.

Methods: Different formulations of repaglinide floating tablets were prepared with different grades of hydroxypropyl methylcellulose (HPMC) and other agents. Evaluation parameters and in vivo bioavailability studies were conducted in the suitable model.

Results: Among all the formulations, F21 containing HPMC K1500 PH PRM, Polyox WSR 303, and sodium bicarbonate, as gas generating agent was selected as optimized formulation based on physicochemical properties, floating lag time (36 s), and total floating time ( $>24 \mathrm{~h}$ ). From in vitro dissolution studies, the optimized formulation F21 showed drug release of $98.92 \pm 5.19 \%$ within 24 h whereas $95.09 \pm 5.01 \%$ of the drug was released from the marketed product within $1 \mathrm{~h}$.

Conclusion: From in vitro and in vivo bioavailability studies repaglinide floating tablets expected to give a new choice for safe, economical, and increased bioavailability for effective management of diabetes mellitus.

Keywords: Repaglinide, Floating tablets, Hydroxypropyl methylcellulose K1500 PH PRM, Diabetes mellitus, Bioavailability studies.

(C) 2018 The Authors. Published by Innovare Academic Sciences Pvt Ltd. This is an open access article under the CC BY license (http://creativecommons. org/licenses/by/4. 0/) DOI: http://dx.doi.org/10.22159/ajpcr.2018.v11i7.25776

\section{INTRODUCTION}

Using current release technology, oral delivery for $24 \mathrm{~h}$ is possible for many drugs; however, the substance must be absorbed well throughout the whole gastrointestinal tract [1]. Most of the drug delivery systems are from ODDS [2]. Based on the requirement, formulations can be changed from immediate release to extended release using several polymers [3]. Gastroretentive floating dosage forms are continuously researched and developed as the stomach is a major absorption zone. The gastric emptying time which varies from 2 to $3 \mathrm{~h}$ is a disadvantage for gastroretentive dosage forms. Based on the formulation type and physiological condition of the patient, the gastric emptying process can vary from a few minutes to $12 \mathrm{~h}$ also. This variation may lead to unpredictable bioavailability and times to achieve peak plasma levels $[4,5]$. While the system remains afloat, the drug is released at the desired rate from the system [6]. Following drug release, the residual system gets emptied from the stomach. This results in an increased gastric retention time and better control of the fluctuations in plasma drug concentration. $[7,8]$.

Repaglinide comes under type II diabetes. It stimulates the release of insulin by binding to a receptor that is distinct from sulfonylurea receptor [9].

The current study focused on the development of a repaglinide matrix floating tablet by achieving the sustained drug release and determining the drug release mechanism optimizing the dosage form in the physical and technological sense and proving the prolongation of the gastric residence time on beagle dogs.

\section{MATERIALS AND METHODS}

Materials

Repaglinide was procured from Aurobindo Pharma Ltd., Hyderabad. Hydroxypropyl methylcellulose (HPMC) K250 PH PRM, HPMC K750 PH PRM, and HPMC K1500 PH PRM were obtained from Ashland India Pvt.
Ltd., Hyderabad. POLYOX WSR 303 was obtained from Granules India Ltd, Hyderabad. Sodium bicarbonate, MCC, talc and magnesium stearate were procured from SD Fine Ltd., Mumbai, and all other chemicals used were of analytical grade.

\section{Methods}

\section{Evaluation of final blend}

The final blend of all formulations was evaluated for bulk density, tapped density, compressibility index, Hausner ratio, and angle of repose [10].

\section{Formulation method}

Accurately weighed amounts of MCC, polymers, and drug (repaglinide) were mixed gently by taking in motor and pestle [8]. To that exactly weighed the amount of sodium bicarbonate was taken separately in a mortar and powdered with a pestle. The powder is passed through sieve no 40 . The entire powder is taken in a bag of plastic and mixed well [11]. Finally, magnesium stearate ( $5 \mathrm{~min}$ ) and talc ( $2 \mathrm{~min}$ ) were added and mixed [12]. The mixture equivalent to $300 \mathrm{mg}$ was compressed into tablets with $10 \mathrm{~mm}$ round concave punches at a hardness of $6 \mathrm{~kg} / \mathrm{cm}^{2}$. The composition of floating matrix tablets of repaglinide with different polymers is shown in Tables 1-3.

\section{Evaluation of floating matrix tablets of repaglinide}

Evaluation parameters such as weight variation [13], thickness, hardness [13], friability [14], in vitro buoyancy studies [15], and drug content [16] were evaluated according to the reported methods.

\section{In vitro drug release studies}

The in vitro drug release study was performed for the single and multiple-unit tablets using USP Type II dissolution apparatus using $900 \mathrm{ml}$ of $0.1 \mathrm{~N} \mathrm{HCl}$ at a temperature of $37 \pm 0.5^{\circ} \mathrm{C}$ at $50 \mathrm{rpm} .5 \mathrm{ml}$ of sample was collected at $0,2,4,6,8,12,16,20$, and $24 \mathrm{~h}$ and the same 
Table 1: Composition of floating matrix tablets of repaglinide with HPMC K250 PH PRM

\begin{tabular}{|c|c|c|c|c|c|c|c|}
\hline \multirow[t]{2}{*}{ Ingredients (weight in mg) } & \multicolumn{7}{|c|}{ Formulations } \\
\hline & F1 & F2 & F3 & F4 & F5 & F6 & F7 \\
\hline Repaglinide & 10 & 10 & 10 & 10 & 10 & 10 & 10 \\
\hline POLYOX WSR 303 & 30 & 30 & 30 & 30 & 30 & 30 & 30 \\
\hline Sodium bicarbonate & 20 & 22 & 24 & 26 & 28 & 30 & 32 \\
\hline MCC & 144 & 132 & 120 & 108 & 96 & 84 & 72 \\
\hline Talc & 3 & 3 & 3 & 3 & 3 & 3 & 3 \\
\hline Magnesium stearate & 3 & 3 & 3 & 3 & 3 & 3 & 3 \\
\hline Total weight & 300 & 300 & 300 & 300 & 300 & 300 & 300 \\
\hline
\end{tabular}

HPMC: Hydroxypropyl methylcellulose

Table 2: Composition of floating matrix tablets of repaglinide with HPMC K750 PH PRM

\begin{tabular}{|c|c|c|c|c|c|c|c|}
\hline \multirow[t]{2}{*}{ Ingredients (weight in mg) } & \multicolumn{7}{|c|}{ Formulations } \\
\hline & F8 & F9 & F10 & F11 & F12 & F13 & F14 \\
\hline Repaglinide & 10 & 10 & 10 & 10 & 10 & 10 & 10 \\
\hline HPMC K750 PH PRM & 90 & 100 & 110 & 120 & 130 & 140 & 150 \\
\hline POLYOX WSR 303 & 30 & 30 & 30 & 30 & 30 & 30 & 30 \\
\hline Sodium bicarbonate & 20 & 22 & 24 & 26 & 28 & 30 & 32 \\
\hline MCC & 144 & 132 & 120 & 108 & 96 & 84 & 72 \\
\hline Talc & 3 & 3 & 3 & 3 & 3 & 3 & 3 \\
\hline Magnesium stearate & 3 & 3 & 3 & 3 & 3 & 3 & 3 \\
\hline Total weight & 300 & 300 & 300 & 300 & 300 & 300 & 300 \\
\hline
\end{tabular}

HPMC: Hydroxypropyl methylcellulose

Table 3: Composition of floating matrix tablets of repaglinide with HPMC K1500 PH PRM

\begin{tabular}{|c|c|c|c|c|c|c|c|}
\hline \multirow[t]{2}{*}{ Ingredients (weight in mg) } & \multicolumn{7}{|c|}{ Formulations } \\
\hline & F15 & F16 & F17 & F18 & F19 & F20 & F21 \\
\hline Repaglinide & 10 & 10 & 10 & 10 & 10 & 10 & 10 \\
\hline POLYOX WSR 303 & 30 & 30 & 30 & 30 & 30 & 30 & 30 \\
\hline Sodium bicarbonate & 20 & 22 & 24 & 26 & 28 & 30 & 32 \\
\hline MCC & 144 & 132 & 120 & 108 & 96 & 84 & 72 \\
\hline Talc & 3 & 3 & 3 & 3 & 3 & 3 & 3 \\
\hline Magnesium stearate & 3 & 3 & 3 & 3 & 3 & 3 & 3 \\
\hline Total weight & 300 & 300 & 300 & 300 & 300 & 300 & 300 \\
\hline
\end{tabular}

HPMC: Hydroxypropyl methylcellulose

Table 4: Comparison of pharmacokinetic parameters of repaglinide optimized formulation and marketed product

\begin{tabular}{lll}
\hline Parameters & Repaglinide optimized formulation (F21) & Marketed product \\
\hline $\mathrm{C}_{\text {max }}(\mathrm{ng} / \mathrm{ml})$ & $200 \pm 3.8$ & $184 \pm 3.7$ \\
$\mathrm{AUC}_{0-\mathrm{t}}(\mathrm{ng} . \mathrm{h} / \mathrm{ml})$ & $3176 \pm 56.44$ & $2597 \pm 44.26$ \\
$\mathrm{AUC}_{0-\infty}(\mathrm{ng} \cdot \mathrm{h} / \mathrm{ml})$ & $3325 \pm 28.14$ & $2826.25 \pm 38.12$ \\
$\mathrm{~T}_{\text {max }}(\mathrm{h})$ & $4.00 \pm 1.23$ & $1.50 \pm 0.24$ \\
$\mathrm{t} 1 / 2(\mathrm{~h})$ & $9.053 \pm 0.519$ & $3.164 \pm 0.01$ \\
$\mathrm{Kel}\left(\mathrm{h}^{-1}\right)$ & $0.051 \pm 0.016$ & $0.084 \pm 0.018$ \\
\hline
\end{tabular}

volume of fresh media was replenished [17]. The drug content in the samples was estimated using UV visible spectrophotometer at $231 \mathrm{~nm}$.

\section{Stability studies}

Stability testing was conducted at $40^{\circ} \mathrm{C} \pm 2^{\circ} \mathrm{C} / 75 \% \mathrm{RH} \pm 5 \% \mathrm{RH}$ for 3 months using stability chamber (Thermo Lab, Mumbai). Samples were withdrawn at predetermined intervals $0,30,90$, and 180 days period according to ICH guidelines [18]. Various in vitro parameters such as drug content, in vitro release studies and floating lag time were evaluated.

\section{Animal preparation}

Twelve New Zealand white rabbits of either sex rabbits were (weighing 2-3 kg) selected for this study, all the animals were healthy during the period of the experiment. Animals were maintained at room temperature $25^{\circ} \mathrm{C}, \mathrm{RH} 45 \%$, and $12 \mathrm{~h}$ alternate light and dark cycle with $100 \%$ fresh air exchange in animal rooms, uninterrupted power and water supply and rabbits were fed with standard diet and water ad libitum. The committee no is $1292 /$ ac/09/CPCSEA/21/A.

\section{In vivo study design}

Rabbits were randomly divided into 2 groups each group contains six animals. The Group A rabbits were fed with repaglinide optimized formulation and Group B fed with innovator product with equivalent dose to animal body weight. Blood samples (approximately $0.5 \mathrm{ml}$ ) were obtained with syringes by marginal ear vein at regular intervals $0,0.5,1,1.5,2,4,6,8,12,16,20$, and $24 \mathrm{~h}$ post doses. During collection, 


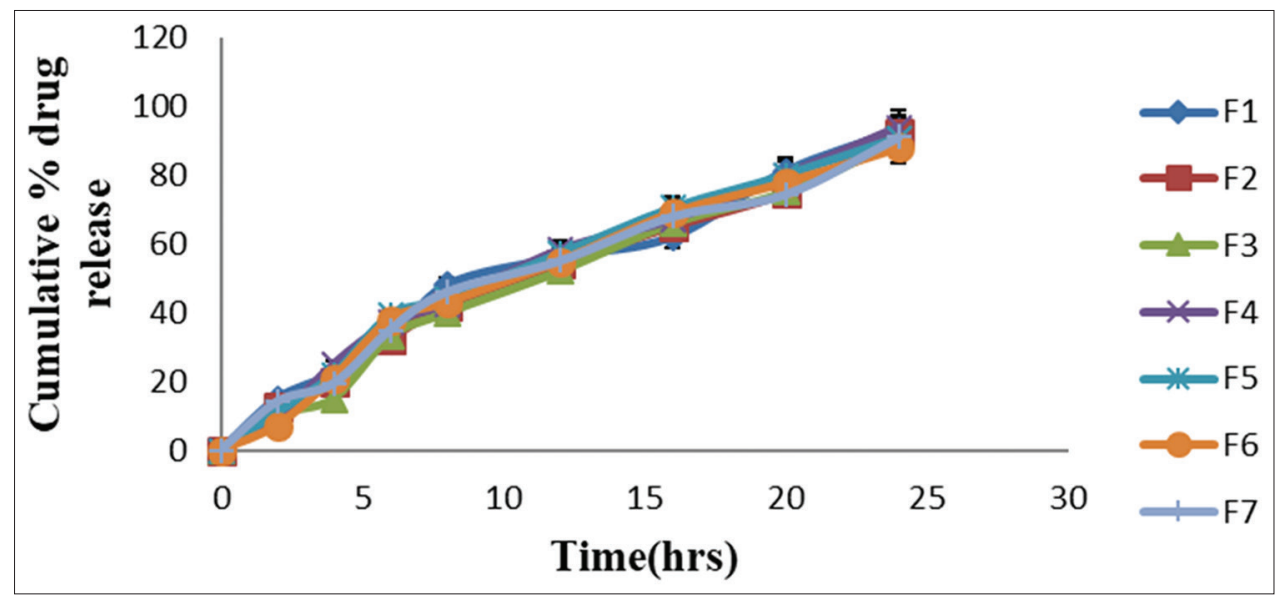

Fig. 1: In vitro drug release profile of repaglinide floating tablets F1-F7

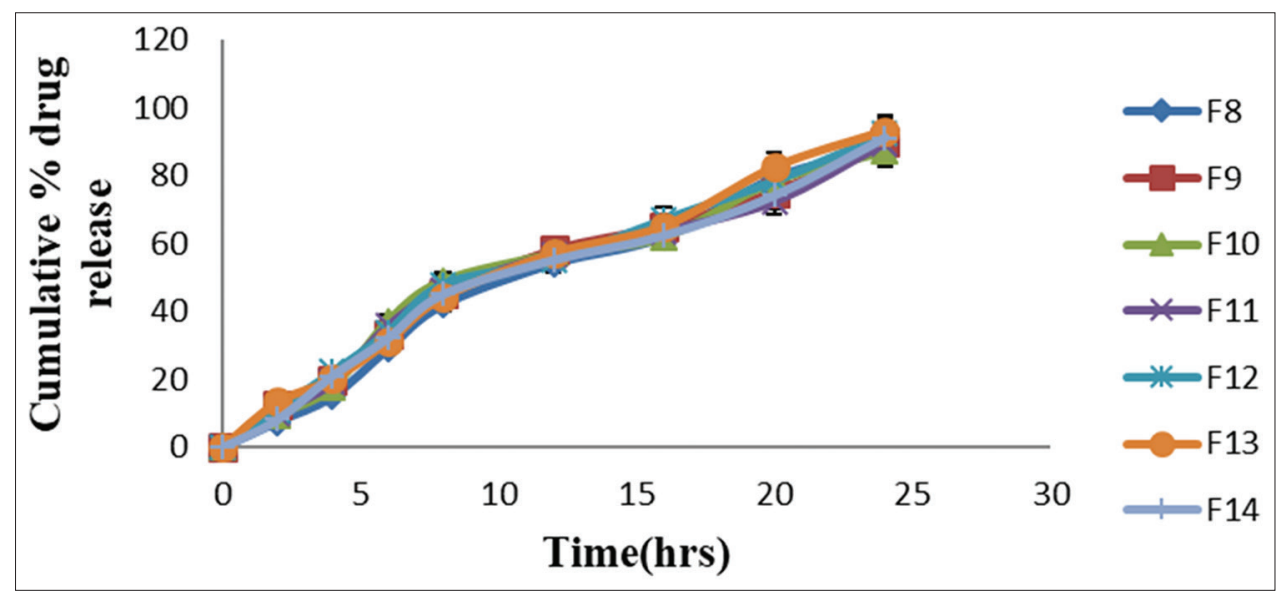

Fig. 2: In vitro drug release profile of repaglinide floating tablets F8-F14

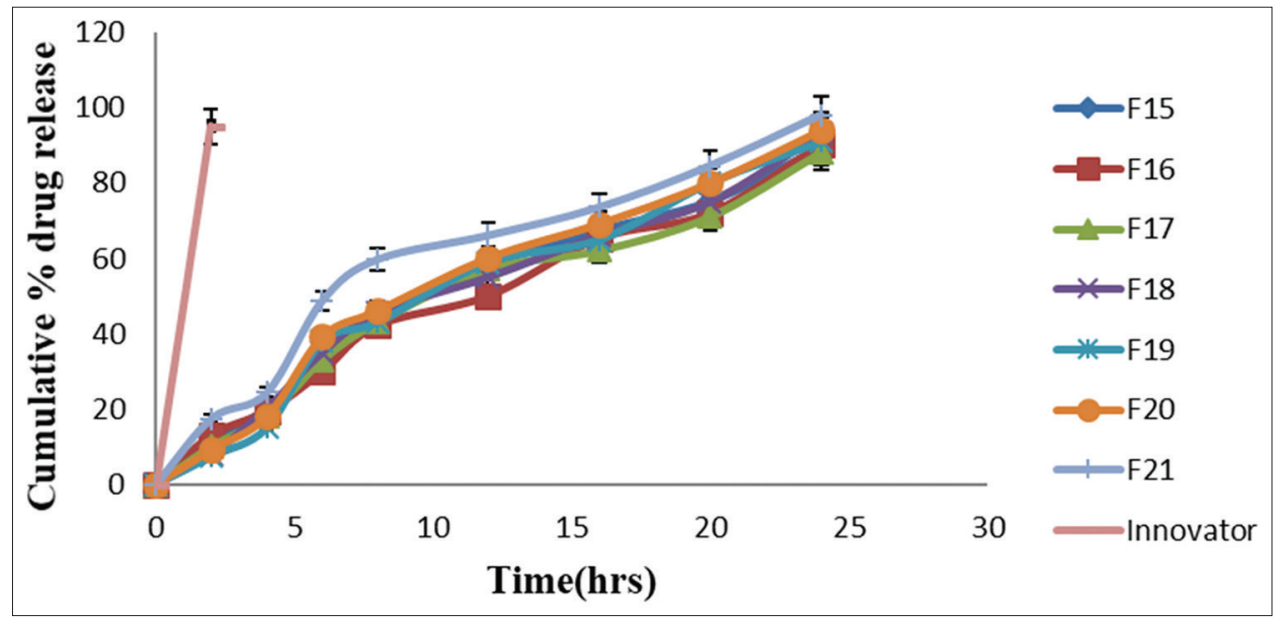

Fig. 3: In vitro drug release profile of repaglinide floating tablets F15-F21 and innovator

blood sample has been mixed thoroughly with heparin to prevent blood clotting. Plasma was separated by centrifugation of the blood at $5000 \mathrm{rpm}$ in cooling centrifuge for $5 \mathrm{~min}$ to $10 \mathrm{~min}$ and stored frozen at $-20^{\circ} \mathrm{C}$ until analysis [19].

Determination of repaglinide in rabbit plasma by highperformance liquid chromatography (HPLC) method Determination of repaglinide using internal standard metformin by HPLC with a RP-C18 chromatographic column, Phenomenex
Kinetex $(150 \mathrm{~mm} \times 4.6 \mathrm{~mm} \quad$ i.d $)$ and a mobile phase consisting of acetonitrile: phosphate buffer $\mathrm{pH} 4.0$ at $60: 40 \% \quad \mathrm{v} / \mathrm{v}$ with $1 \%$ triethylamine at flow rate of 0.8 $\mathrm{ml} / \mathrm{min}$ and at fixed wavelength of $254 \mathrm{~nm}$.

Preparation of plasma samples for HPLC analysis Rabbit plasma $(0.5 \mathrm{ml})$ was prepared for chromatography by precipitating proteins with $2.5 \mathrm{ml}$ of ice-cold absolute ethanol for each $0.5 \mathrm{ml}$ of plasma. After centrifugation, the ethanol was transferred into 


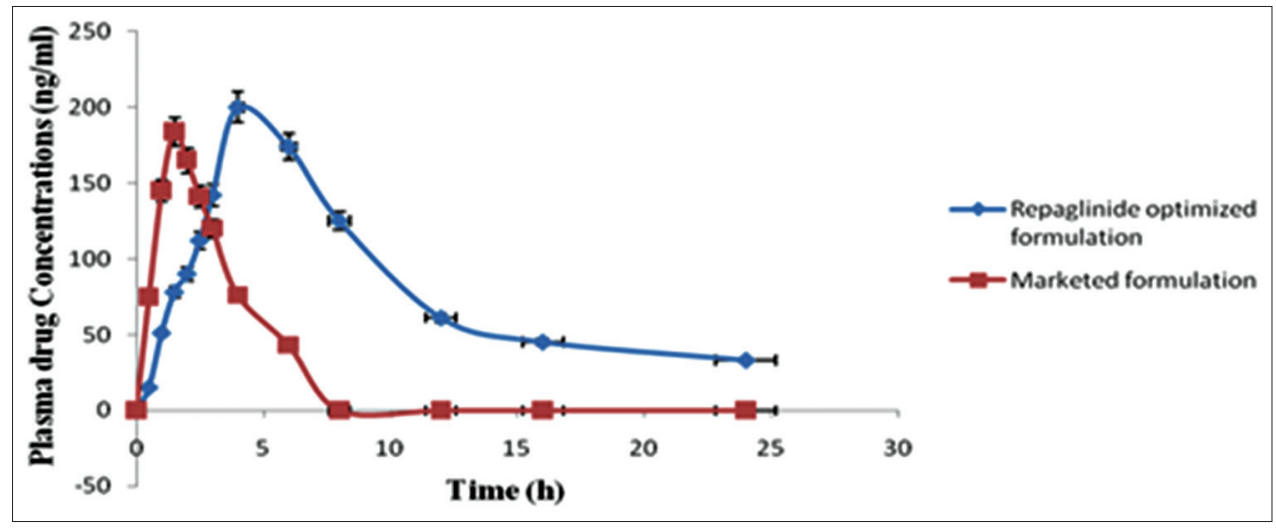

Fig. 4: Plasma concentrations at different time intervals for repaglinide optimized formulation and marketed product

a clean tube. The precipitate was resuspended with $1 \mathrm{ml}$ of acetonitrile by vortexing for $1 \mathrm{~min}$ sample was reconstituted and tested for HPLC analysis.

\section{Pharmacokinetic analysis}

The pharmacokinetic parameters, peak plasma concentrations $\left(\mathrm{C}_{\max }\right)$, and time to reach peak concentration $\left(\mathrm{t}_{\max }\right)$ were directly obtained from concentration-time data. In the present study, area under the curve (AUC) $)_{0-\mathrm{t}}$ refers to the AUC from 0 to $24 \mathrm{~h}$, which was determined by linear trapezoidal rule and $\mathrm{AUC}_{0-\alpha}$ refers to the AUC from time at $0 \mathrm{~h}$ to infinity.

Calculated using the formula $\mathrm{AUC}_{0-\mathrm{t}}+\left[\mathrm{C}_{\text {last }} / \mathrm{K}\right]$ where $\mathrm{C}$ last is the concentration in $\mathrm{mg} / \mathrm{ml}$ at the last time point and $\mathrm{K}$ is the elimination rate constant.

Various pharmacokinetic parameters like AUC, elimination half-life $\left(\frac{1}{t} / 2\right)$. Volume of distribution $\left({ }_{v} d\right)$, total clearance $\left(C_{1} T\right)$ and mean residence time for each subject using a non compartmental pharmacokinetic program.

\section{RESULTS AND DISCUSSION}

All the formulations were evaluated for different parameters such as weight variation, thickness, hardness, friability, in vitro buoyancy studies, and drug content and found to be within the IP limits.

\section{In vitro dissolution studies}

From Figs. 1-3, it can be observed that the polymer HPMC K1500 PH PRM has controlling effect on the release of drug from the floating matrix tablet of repaglinide compared to HPMC K250 PH PRM and HPMC K750 PH PRM. The difference in the drug release profiles of various formulations was due to the presence of different concentrations of polymer HPMC K1500 PH PRM. The concentration of polymer was added in increasing order to check its drug release retarding ability, and F21 was considered as best formulation among the all the formulations. F21 showed good buoyancy properties and controlled the drug release for a desired period $(24 \mathrm{~h})$. The optimized formulation F21 was shown drug release of $98.92 \%$ within $24 \mathrm{~h}$ and $95.09 \%$ of the drug was released from the marketed product within $1 \mathrm{~h}$.

\section{Stability studies}

There were no changes observed in percentage drug content, in vitro drug release studies and floating lag time during storage of the optimized formulation for 6 months; hence, the optimized formulation was found to be stable.

\section{In vivo bioavailability parameters}

Mean plasma concentration profiles of prepared Repaglinide optimized formulation and marketed product are presented in Fig. 4. Repaglinide optimized formulation exhibited a sustained release in vivo when compared with a marketed tablet. All the pharmacokinetics parameters displayed in Table 4. In this study in rabbits, prolonged drug absorption was achieved with the test formulation. The average peak concentration of the test formulation was significantly higher than that of the reference $(200 \pm 3.8 \mathrm{ng} / \mathrm{ml}$ for the test formulation vs. $184 \pm 3.7 \mathrm{ng} / \mathrm{ml}$ for the reference). To estimate the amount of drug absorbed from the test formulation, the relative bioavailability was calculated from the AUC of the reference and test formulations $(2826.25 \pm 38.12 \mathrm{ng} / \mathrm{h} / \mathrm{ml}$ for the reference product vs. $3325 \pm 28.14 \mathrm{ng} / \mathrm{h} / \mathrm{ml}$ for the test formulation). The results indicated that the test formulation could increase the bioavailability of repaglinide in rabbits effectively. In this study, the Repaglinide floating tablet produces higher bioavailability than that of a marketed product, this overall increase in bioavailability and increased gastric residence time, caused by flotation of the dosage form in the stomach.

\section{CONCLUSION}

In the present work, it can be concluded that the Repaglinide floating tablets can be an innovative and promising approach for the delivery of repaglinide for the treatment of diabetes mellitus. The optimized formulation F21 contains HPMC K1500 PH PRM, Polyox WSR 303, and gas-generating agent. In vitro release profile of repaglinide and marketed product when compared, the optimized formulation F21 showed drug release of $98.92 \pm 5.19 \%$ within $24 \mathrm{~h}$ whereas $95.09 \pm 5.01 \%$ of the drug was released from the marketed product within $2 \mathrm{~h}$. The release rate constant of optimized formulation F21 was low enough prolonging drug delivery. From in vivo bioavailability studies repaglinide floating tablets expected to give a new choice for safe, economical, and increased bioavailability for effective management of diabetes mellitus. This study is encouraging because a longer gastric residence time is an important condition for higher bioavailability of the drugs included in the prolonged or controlled release dosage form.

\section{AUTHOR'S CONTRIBUTION}

All the authors have contributed equally.

\section{CONFLICTS OF INTEREST}

No conflicts of interest were raised by the authors.

\section{REFERENCES}

1. Deshpande AA, Rhodes CT, Shah NH. Controlled release drug delivery system for prolonged gastric residence an overview. Drug Dev Ind Pharm 1996;22:531-9.

2. Hibaezzathamed, Kamal BA. Preparation and in-vitro evaluation of desloratadine floating tablet. Int J Pharm Pharm Sci 2015;6:154-9.

3. Whiteheadz L, Fell JT, Collett JH. Development of a gastroretentive dosage form. Eur J Pharma Sci 1996;4:182.

4. Mojaverian P, Vlasses PH, Kellner PE, Rocci M. Effects of gender, posture and age on gastric residence time of an indigestible solid pharmaceutical considerations. Pharm Res 1988;10:639-44.

5. Hwang SK, Park H, Park K. Gastric retentive drug delivery systems. 
Crit Rev Ther Drug Carrier Syst 1998;15:243-84.

6. Siepmann J, Kranz H, Bodmeier R, Peppas NA. HPMC-matrices for controlled drug delivery a new model combining diffusion, swelling, and dissolution mechanisms and predicting the release kinetics. Pharm Res 1999;16:1748-56

7. Chokshi MM, Gupta MM, Gupta M. Formulation development and evaluation of gastroretentive Floating tablet of Ciprofloxacin Hydrochloride. Int J Pharm Pharm Sci 2016;8:148-52.

8. Desai S, Bolton S. A floating controlled release drug delivery system in vitro-in vivo evaluation. Pharma Res 1993;10:1321-5.

9. Culy C, Jarvis B. Repaglinide a review of its therapeutic use in type 2 diabetes mellitus. Drugs 2001;61:1625-60.

10. Li S, Lin S, Chien TW, Daggy BP, Mirchandani HL. Statistical optimization of gastric floating system for oral controlled delivery of calcium. AAPS Pharm Sci Tech 2001;2:783-93.

11. Martindale. The Complete Drug Reference 1996;35:766-79.

12. Rao TR, Krishna KB, Hussain MA, Anjum M, Rahman MA

Formulation and evaluation of gastroretentive floating tablets of quetiapine fumarate. Res J Pharm Biol Chem Sci 2014;5:975-8585.

13. Peppas NA. Analysis of fickian and non-fickian drug release from polymers. Pharm Acta Helv 1985;60:110-1.

14. Nasrin N, Zaman MA, Mowla R, Rizwan F, Alam A. A comparative study of physical parameters of selected ketorolac tromethamine tablets available in the pharma market of Bangladesh. J Appl Pharm Sci 2008; $1: 101-3$

15. Penners G, Lustig K, Jorg PV. Inventors. Expandable Pharmaceutical Forms. US Patent No. 5. 1997. p. 651-985.

16. Phuapradit W, Bolton S. Influence of tablet density on oral absorption of sustained release acetaminophen matrix tablets. Drug Dev Ind Pharm 1991;17:1097-107.

17. Phuapradit W. Influence of tablet buoyancy on oral absorption of sustained release acetaminophen matrix tablets. Jamaica, NY: St John's University; 1989.

18. Tyagi LK, Kori ML. Stability study and in-vivo evaluation of lornoxicam loaded ethyl cellulose microspheres. Int J Pharm Sci Drug Res 2014;6:26-30.

19. Kadivar A, Kamalidehghan B, Javar HA, Davoudi ET, Zaharuddin ND, Sabeti B, et al. Formulation and In vitro, in vivo evaluation of effervescent floating sustained-release imatinib mesylate tablet. PLoS One 2015;10:e126874. 